\title{
Comparison of high-dose intravenous methylprednisolone with low-dose oral prednisolone in acute renal allograft rejection in children
}

\author{
NELSON ORTA-SIBU, CYRIL CHANTLER, MICHAEL BEWICK, GEORGE HAYCOCK
}

\begin{abstract}
Two corticosteroid regimens were compared in a randomised, prospective study of 48 consecutive acute rejection episodes occurring at least one month after transplantation in 22 children who had received renal allografts. The higher dose schedule (intravenous methylprednisolone $600 \mathrm{mg} / \mathrm{m}^{2}$ daily for three days) was no more effective than the lower (oral prednisolone $3 \mathrm{mg} / \mathrm{kg}$ daily for three days) in reversing rejection, being successful in $70 \%$ as opposed to $72 \%$ of episodes. Few major side effects were seen with either treatment, but unpleasant sensations were reported much more frequently in the group given intravenous methylprednisolone; this regimen was also much more disruptive of the patient's life.

Oral prednisolone in the dosage described is as effective as about 10 times that dose of intravenous methylprednisolone; it is much cheaper and is viewed as less unpleasant by patients.
\end{abstract}

\section{Introduction}

In the past decade renal transplantation, originally available only to selected young adults, has been applied with increasing success to both older and younger patients. Recent reports ${ }^{1-4}$ indicate that results even in quite young children are comparable with those obtained in adults with respect to both patient and graft survival, so that age alone can no longer be regarded as a contraindication to this form of treatment.

Immunosuppressive treatment is central to the medical management of transplant recipients. Corticosteroids are invariably used as part of the "background" immunosuppressive regimen, in doses sufficient to produce appreciable toxicity in almost all patients, particularly during the first postoperative year. In addition, acute rejection episodes are treated by increasing the steroid dose, with the result that patients who suffer frequent acute rejection episodes usually suffer severe side effects. A recent, retrospective study ${ }^{5}$ of adult patients treated in a large transplant centre suggested that mortality and morbidity had fallen substantially after the adoption of a less aggressive antirejection policy, without a concomitant increase in graft loss. We therefore undertook the present study to compare prospectively the effectiveness of high-dose intravenous methylprednisolone and low-dose oral prednisolone in reversing acute rejection episodes and, secondly, the incidence and severity of side effects produced by the two regimens.

Evelina Department of Paediatrics and Renal Transplant Unit, Guy's Hospital, London SE1 9RT

NELSON ORTA-SIBU, MD, research fellow (now lecturer in paediatrics, Hospital General de Valencia, Venezuela)

MICHAEL BEWICK, MCHIR, FRCS, consultant transplant surgeon

CYRIL CHANTLER, MD, FRCP, professor of paediatric nephrology

GEORGE B HAYCOCK, MB, FRCP, consultant paediatric nephrologist

\section{Patients and methods}

The study group comprised children aged less than 15 years who had received a renal allograft at this hospital. A total of 48 consecutive acute rejection episodes occurring at least one month after transplantation were studied in 22 patients, of whom 14 had received live donor and eight cadaveric grafts. Acute rejection episodes occurring during the first month after transplantation were treated with high-dose methylprednisolone and were not included in the analysis.

Acute rejection episodes were diagnosed on the basis of a $20 \%$ rise in plasma creatinine concentration, confirmed on a repeat specimen, for which no other cause (urinary infection, obstruction, hyperglycaemia, etc) could be found. Clinical signs of rejection (fever, graft tenderness, weight gain, hypertension) and deterioration in graft perfusion (technetium-99m pentetic acid renal scan ${ }^{6}$ ) supported the diagnosis in most cases.

When an acute rejection episode was diagnosed the patient was randomly assigned to one of two treatment protocols by a sealed envelope withdrawn blind from a box being opened. Each rejection episode was treated as an independent event; thus the same patient might appear in both treatment groups if he was treated more than once during the study. The two treatment courses were oral prednisolone $3 \mathrm{mg} / \mathrm{kg}$ and intravenous methylprednisolone $600 \mathrm{mg} / \mathrm{m}^{2}$ each given as a single daily dose on each of three consecutive days. Background steroid treatment was interrupted for these three days and resumed the next day at the previous dosage; other treatment was continued unchanged. Patient response was evaluated daily during treatment and again one and two weeks after the start of treatment by assessment of clinical state, weight, blood pressure, and plasma creatinine concentration. The pentetic acid scan was repeated at the two-week assessment. Rejection was deemed to have been reversed if pretreatment values were restored with respect to plasma creatinine concentration, pentetic acid scan flow index, and clinical signs; incomplete responses were classified as failures.

\section{Results}

Table I shows the results of the randomisation procedure and the proportion of acute rejection episodes reversed by each treatment.

TABLE I-Comparison of treatment groups

\begin{tabular}{lcc}
\hline & $\begin{array}{c}\text { Oral } \\
\text { prednisolone }\end{array}$ & $\begin{array}{c}\text { Intravenous } \\
\text { methylprednisolone }\end{array}$ \\
\hline No in group & 25 & 23 \\
Mean age (years) & $12 \cdot 0$ & $12 \cdot 3$ \\
Male:female & $16: 9$ & $12: 11$ \\
Live donor:cadaver grafts & $14: 11$ & $17: 6$ \\
Months after transplantation (mode) & $2 \cdot 0$ & $2 \cdot 5$ \\
No of acute rejection episodes reversed & $18(72 \%)$ & $16(70 \%)$ \\
\hline
\end{tabular}

The two treatment groups did not differ significantly with respect to age, sex ratio, source of kidney (live donor $v$ cadaver), time elapsed since transplantation, or plasma creatinine concentration immediately before rejection. Eighteen out of 25 acute rejection episodes (72\%) were reversed by oral prednisolone and 16 out of $23(70 \%)$ by intravenous methylprednisolone; this difference was not significant.

Figure 1 shows the effect of treatment on plasma creatinine concentration in all patients and figure 2 the effect in those in whom treatment was successful. Although there was some apparent delay in the fall in concentration in the group given intravenous methylprednisolone (fig 1), the difference between the two groups did not approach significance at any time during the two-week study period. Comparison 
Antirejection treatment
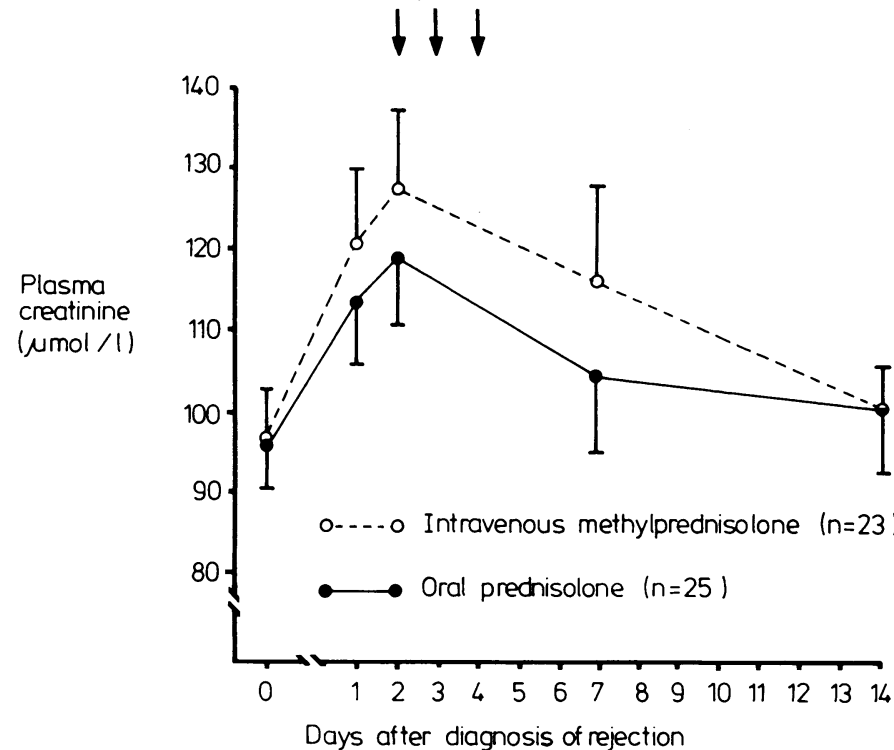

FIG $1-$ Mean $\pm S E M$ plasma creatinine concentrations in the two treatmen groups (all patients). Baseline value (day 0 ) is the last estimation recorded before rejection was diagnosed.

Conversion: SI to traditional units-Creatinine: $1 \mu \mathrm{mol} / 1 \approx 11 \cdot 3 \mu \mathrm{g} / 100 \mathrm{ml}$.

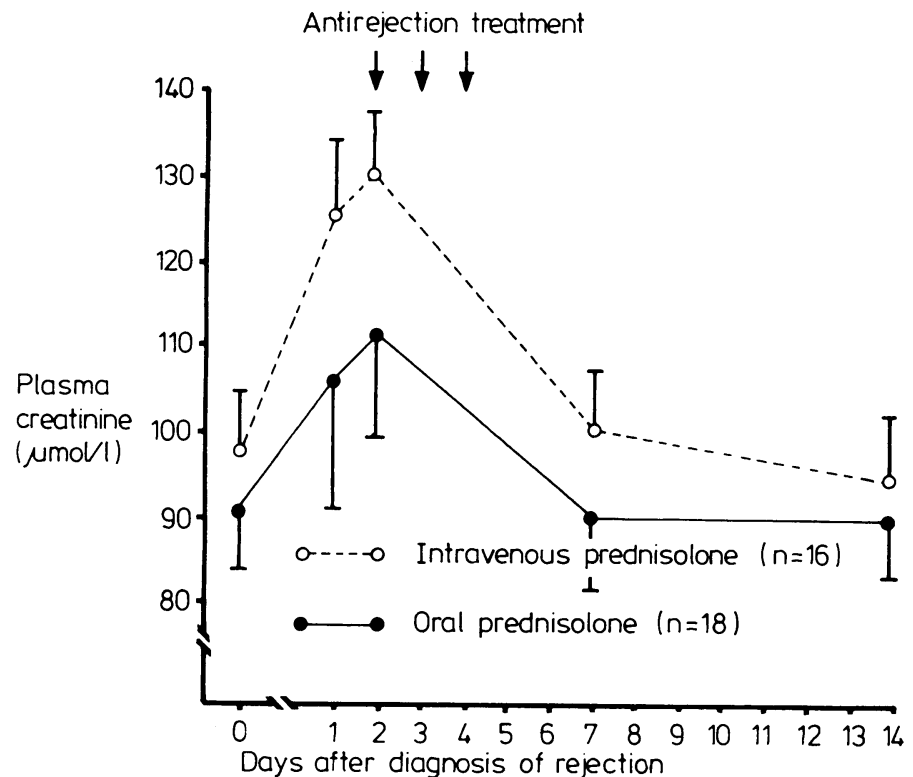

FIG 2-Mean $\pm S E M$ plasma creatinine concentrations in patients in the two treatment groups in whom treatment was successful.

Conversion: SI to traditional units-Creatinine: $1 \mu \mathrm{mol} / 1 \approx 11 \cdot 3 \mu \mathrm{g} / 100 \mathrm{ml}$.

of figures 1 and 2 suggests that this effect was wholly due to those patients who failed to respond to treatment.

Few side effects were seen with either treatment; these are summarised in table II. Patients receiving intravenous methylprednisolone, however, disliked the injections and the peculiar sensations experienced during the infusion.

Figure 3 summarises the outcome of the 14 acute rejection episodes that were not reversed. The only rejection that led to graft loss was in a patient given intravenous methylprednisolone; otherwise the outcome was identical in the two groups.

\section{Discussion}

Various regimens have been advocated for the treatment of acute rejection episodes; most entail a substantial increase in corticosteroid dosage, either by mouth ${ }^{78}$ or by using large doses of intravenous methylprednisolone. ${ }^{9-11}$ Few comparative trials of different treatments have been published, however, and none at all in children. Clarke and Salaman ${ }^{12}$ found that oral prednisolone and intravenous methylprednisolone were equally effective in reversing acute rejection episodes, no further improvement being achieved even when both were used together. The overall incidence of side effects was similar in all groups, though life-threatening complications such as septicaemia, pneumonia, and gastrointestinal haemorrhage were more common in patients given oral prednisolone. Similar results were described by Mussche $e t a l^{13}$ in 1976 and by Gray et $a l^{14}$ in 1978. The high incidence of serious toxicity in these series, particularly in patients treated with oral prednisolone, may have been attributable to the fact that the drug was administered in divided daily doses, thus presumably achieving continuously high blood steroid concentrations, whereas the intravenous methylprednisolone was given as boluses, thus achieving transiently high concentrations but with return to baseline values before the next dose. Furthermore, the two- or three-day course of either drug was followed in most cases by a further period of "tailing off" down to the background immunosuppressive regimen, which might be expected to increase toxicity further.

In contrast to the above, a group in San Francisco ${ }^{15}$ found that the introduction of a less aggressive immunosuppressive policy in 1972, including among other things a change from intravenous methylprednisolone to oral prednisolone, was followed by a reduction in patient mortality and morbidity without any increase in graft loss; a later report ${ }^{5}$ confirmed that the improvement in results was sustained. Kauffmann $e \mathrm{al}^{16}$ recently reported a prospective, double-blind trial comparing high-dose $(30 \mathrm{mg} / \mathrm{kg})$ with low-dose ( $3 \mathrm{mg} / \mathrm{kg}$ ) intravenous methylprednisolone in the treatment of acute rejection episodes. Although the design of this study differed in several respects from that reported here, the steroid dosages being compared were similar. The authors concluded that the higher dosage was no more effective than the lower, while possibly leading to greater toxicity.

Our results show that oral prednisolone in a dose of $3 \mathrm{mg} / \mathrm{kg} /$ day for three days is sufficient to reverse $72 \%$ of acute rejection episodes occurring in children more than one month after transplantation; this is no different from results obtained with intravenous methylprednisolone in either our own series or in

\begin{tabular}{lcc} 
TABLE II-Comparison of side effects & observed \\
\hline & $\begin{array}{c}\text { Oral } \\
\text { prednisolone }\end{array}$ & $\begin{array}{c}\text { Intravenous } \\
\text { methylprednisolone }\end{array}$ \\
\hline Hypertension* & 2 & 2 \\
Weight gain $\dagger$ & 5 & 7 \\
Infection & $1 \ddagger$ & $1 \S$ \\
Miscellaneous & $1 \uparrow$ & $1 \rrbracket$
\end{tabular}
$*$ Defined as diastolic blood pressure $>85 \mathrm{~mm} \mathrm{Hg}$. $\dagger$ Defined
as increase of $>500 \mathrm{~g}$ over pretreatment value. The infections were in the urine $t$ and in an arteriovenous shunt \& miscellaneous complications comprised nausea !! and "feeling unwell."

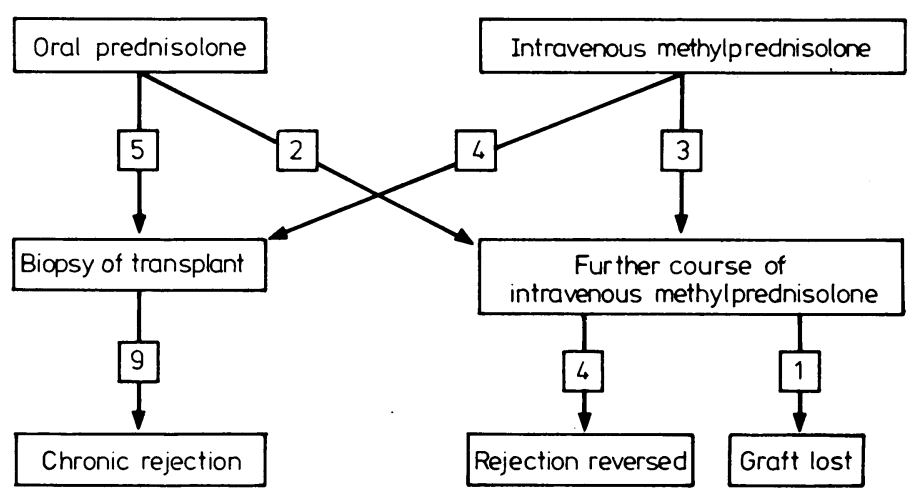

FIG 3-Subsequent course and outcome in patients in whom treatment failed to reverse acute rejection episodes. 
those published by others. ${ }^{12-14}$ The incidence and severity of side effects were low, which we attribute to the following factors: firstly, that the drug was given as a single daily dose; secondly, that on the fourth day the patients returned to the pretreatment steroid dosage, without any "tailing-off" period; and, thirdly, that background steroid treatment was stopped during the three treatment days. Certain additional advantages of oral prednisolone became apparent during the study. Many hospital visits were avoided, since the drug may be taken at home while each dose of intravenous methylprednisolone requires attendance at hospital. By the same token, interruption of school attendance and social activities was much reduced. The patients universally disliked intravenous methylprednisolone, which produces a variety of unpleasant sensations during injection and requires additional needles, a special problem with younger children. Finally, the cost of a course of treatment with oral prednisolone is less than $£ 1$, compared with about $£ 45$ for three doses of intravenous methylprednisolone.

We conclude that oral prednisolone, in three single daily doses of $3 \mathrm{mg} / \mathrm{kg}$, is as effective as high-dose intravenous methylprednisolone in reversing acute rejection episodes in children with renal allografts and is attended by few serious side effects; we recommend its adoption as the treatment of choice in the routine management of paediatric transplant recipients.

We gratefully acknowledge the assistance of Sister Angie Munian, without whose contribution this work would have been impossible. We also thank Miss Ann Chapman for typing the manuscript.

\section{References}

${ }^{1}$ Hodson EM, Najarin JS, Kjellstrand CM, Simmons RL, Maner SM. Renal transplantation in children aged 1 to 5 years. Pediatrics 1978;61: 458-64.
2 Chantler C, Carter JE, Bewick M, et al. 10 years' experience with regular haemodialysis and renal transplantation. Arch Dis Child 1980;55:435-45.

${ }^{3}$ Donckerwolcke RA, Chantler C, Broyer M, et al. Combined report on regular dialysis and transplantation of children in Europe, 1979. Proc Eur Dial Transplant Assoc 1980;17:87-115.

4 Rizzoni G, Malekzadeh MH, Pennisi AJ, Eltenger RB, Uittenbogaart CH, Fine RN. Renal transplantation in children less than 5 years of age. Arch Dis Child 1980;55:532-6.

5 Vincenti F, Amend W, Feduska NJ, Duca RM, Salvatierra O. Improved outcome following renal transplantation with reduction in the immunosuppressive therapy for rejection episodes. Am 7 Med 1980;69:107-12.

6 Burke JR, Counahan R, Hilson AJW, et al. Serial quantitative imaging with ${ }^{99} \mathrm{Tc}^{\mathrm{m}}$ DTPA in paediatric renal transplantation. Clin Nephrol 1979 12:174-7.

${ }^{7}$ Merrill JP. Diagnosis and management of rejection in allografted kidneys. Transplant Proc $1971 ; 3: 287-92$

${ }^{8}$ Simmons RL, Kjellstrand CM, Najarian JS. Kidney transplantation. In: Najarian JS, Simmons RL, eds. Transplantation. Philadelphia: Lea and Febiger, 1972:445.

9 Kountz SL, Cohn R. Initial treatment of renal allografts with large intrarenal doses of immunosuppressive drugs. Lancet $1969 ; \mathrm{i}: 338-40$.

10 Bell PRF, Calman KC, Wood RFM. Reversal of acute clinical experimental organ rejection using large doses of intravenous prednisolone. Lancet 1971 ; $: 876-80$.

11 Turcotte JG, Feduska NJ, Carpenter EW, McDonald FD, Bacon GE. Rejection crises in human renal transplant recipients. Control with high dose methylprednisolone therapy. Arch Surg 1972;105:230-6.

12 Clarke AG, Salaman JR. Methyl prednisolone in the treatment of renal transplant rejection. Clin Nephrol 1974;2:230-4.

13 Mussche MM, Ringoir SMG, Lameire NN. High intravenous doses of methylprednisolone for acute cadaveric renal allograft rejection. Nephron $1976 ; 16: 287-91$.

14 Gray D, Shepherd H, Daar A, Oliver DO, Morris PJ. Oral versus intravenous high-dose steroid treatment of renal allograft rejection: the big shot or not? Lancet 1978 ; : 117-8.

15 Salvatierra O, Potter D, Cochrum KC, et al. Improved patient survival in renal transplantation. Surgery 1976;79:166-71.

${ }^{16}$ Kauffman HM Jr, Stromstad SA, Sampson D, Stawicki AJ. Randomised steroid therapy of human kidney transplant rejection. Transplant Proc $1979 ; 11: 36-8$.

(Accepted 4 June 1982)

\section{SHORT REPORTS}

\section{Arterial complications of migraine treatment with methysergide and parenteral ergotamine}

Cluster headaches, which are associated with abnormal dilatation of the carotid artery and wall oedema, ${ }^{1}$ may be managed with methysergide and ergotamine. These drugs promote arterial constriction. Large artery spasm may rarely complicate treatment with either drug and is more likely when ergotamine is administered parenterally. We report on two patients in whom arterial spasm and tissue infarction developed during concurrent treatment with methysergide and parenteral ergotamine. This combination appears to create a particularly high risk of arterial spasm.

\section{Casé reports}

Case 1-A 34-year-old man who took small amounts of methysergide prophylactically for recurrent cluster headaches and smoked lightly was treated during a cluster with methysergide $2 \mathrm{mg}$ thrice daily and subcutaneous ergotamine tartrate $0.5 \mathrm{mg}$ at night. Seven days after starting this combination he developed right faciobrachial thermoanaesthesia, vertigo, dysphagia, and hoarseness. He continued ergotamine injections for five more days and methysergide for three weeks, when left Horner's syndrome, reduced left gag reflex, and impaired pain, temperature, and light touch sensation over the right face, shoulder, and arm were found. Arteriography disclosed left vertebral artery occlusion for $1.5 \mathrm{~cm}$ upwards from the foramen magnum, collateral circulation, and right vertebral artery spasm (figure). Signs gradually resolved after withdrawal of the drugs, except for persistent right faciobrachial thermoanaesthesia.

Case 2-A 27-year-old man was treated during a bout of cluster headaches with methysergide $2 \mathrm{mg}$ thrice daily, pizotifen $0.5 \mathrm{mg}$ thrice daily, and intramuscular ergotamine tartrate. Oral and rectal ergotamine preparations

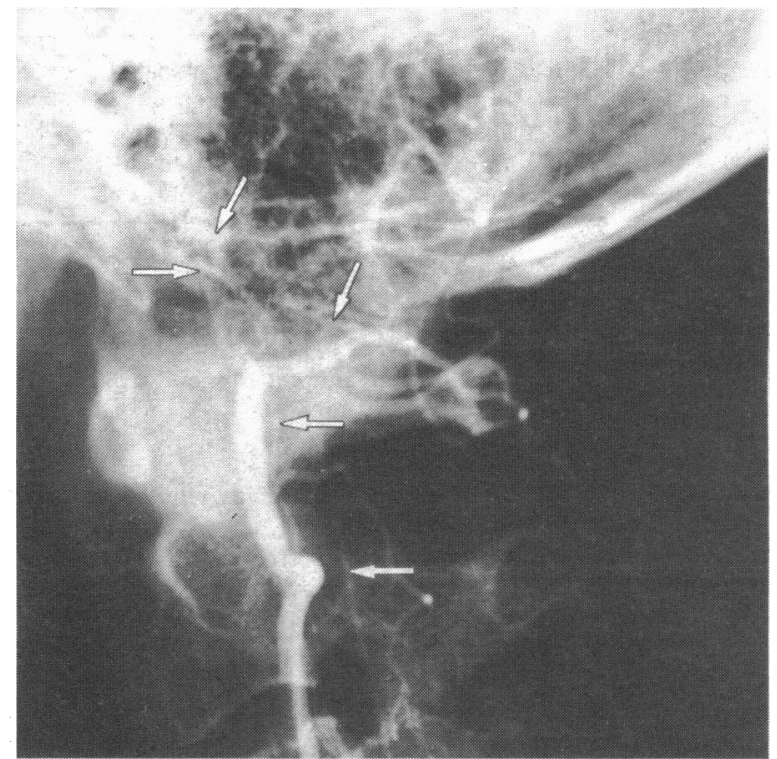

Case 1. Left vertebral arteriogram, lateral view. Oblique arrows indicate proximal and distal ends of occluded vessel; horizontal arrows indicate collateral vessels.

had been ineffective. The dose of parenteral ergotamine was increased from $0.5 \mathrm{mg}$ at night to $1 \mathrm{mg}$ twice daily over 16 days. Three days later popliteal and pedal pulses were impalpable and the right foot was ischaemic. Arteriography disclosed a $22 \mathrm{~cm}$ segment of spasm in the right superficial femoral 